\title{
しホルマリンフによる鼻粘膜刺载の鼻汁並に淚液 分泌に及ぼす影響に就ての實驗的研究
}

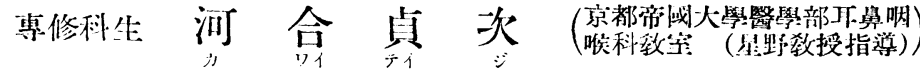

目次
後に於ける場合

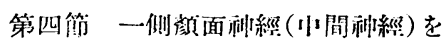
延髄より出たる部に於て切 穙したる後に於ける場合

第三章・總括站に考按

第四章 結 諭

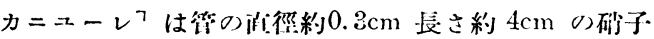

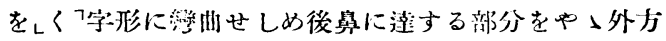
に樞げたるもの)

薬液瓶の他の确子管の一端は水槽レタンクาと連絬し

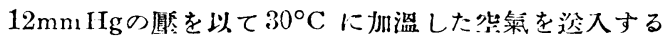
と瓶内 $ム$ ホマリンフによる瓦斯體はしヒョアナールカ ニニーレフを經て鼻腔內に洼するものである.ムホルマ リンフ液は山本藥间法によるものをう倍に水を以て稀 釋し插入せる础子篗に接しない樣に加減する。刺戟時 閒はすよて 1 分閒とし，刺戟開始後からら分後まで， 5 分後から15分後をで，15分後から25分後まで三则に 分ちて分泌物を吸黑紙に吸收せしめて Torsions-Wage で湖定した。(單位 $\mathrm{mg}$ ).

\section{第二章 實 驗 成繶}

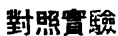

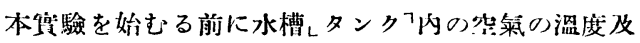
ど厴力の影箤によりては邚何に變化するかを知らんと してレコルペンフ小の刺戟藥の代りに水を入れて筷驗し た。成紹は次表のやらである。 連結する.(ムヒョアナール

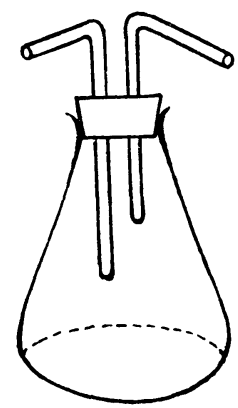

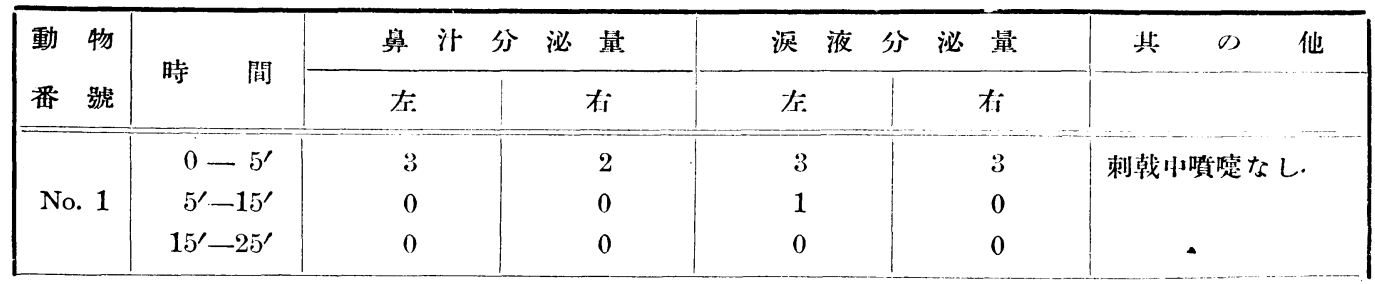




\begin{tabular}{|c|c|c|c|c|c|c|}
\hline No. 2 & $\begin{array}{c}0-5^{\prime} \\
5^{\prime}-15^{\prime} \\
15^{\prime}-25^{\prime}\end{array}$ & $\begin{array}{l}2 \\
0 \\
0\end{array}$ & $\begin{array}{l}2 \\
0 \\
0\end{array}$ & $\begin{array}{l}3 \\
0 \\
0\end{array}$ & $\begin{array}{l}2 \\
2 \\
0\end{array}$ & 刺戟中噴呪 2 回あり. \\
\hline No. 3 & $\begin{array}{c}0-5^{\prime} \\
5^{\prime}-15^{\prime} \\
15^{\prime}-25^{\prime}\end{array}$ & $\begin{array}{l}3 \\
1 \\
0\end{array}$ & $\begin{array}{l}3 \\
0 \\
0\end{array}$ & $\begin{array}{l}3 \\
0 \\
0\end{array}$ & $\begin{array}{l}2 \\
1 \\
0\end{array}$ & 刺战中噴娔なし. \\
\hline No. 4 & $\begin{array}{c}0-5^{\prime} \\
5^{\prime}-15^{\prime} \\
15^{\prime}-25^{\prime}\end{array}$ & $\begin{array}{l}4 \\
1 \\
0\end{array}$ & $\begin{array}{l}2 \\
0 \\
0\end{array}$ & $\begin{array}{l}2 \\
0 \\
0\end{array}$ & $\begin{array}{l}1 \\
0 \\
0\end{array}$ & 刺戟ゆ噴德 3 问あり. \\
\hline No. 5 & $\begin{array}{c}0-5^{\prime} \\
5^{\prime}-15^{\prime} \\
15^{\prime}-25^{\prime}\end{array}$ & $\begin{array}{l}2 \\
0 \\
0\end{array}$ & $\begin{array}{l}3 \\
1 \\
0\end{array}$ & $\begin{array}{l}2 \\
0 \\
0\end{array}$ & $\begin{array}{l}2 \\
0 \\
0\end{array}$ & 刺戟中噴德 2 间あり。 \\
\hline 平均 & $\begin{array}{c}0-5^{\prime} \\
5^{\prime}-15^{\prime} \\
15^{\prime}-25^{\prime}\end{array}$ & $\begin{array}{c}2.8 \\
0.4 \\
0\end{array}$ & $\begin{array}{c}2.4 \\
0.2 \\
0\end{array}$ & $\begin{array}{c}2.6 \\
0.2 \\
0\end{array}$ & $\begin{array}{c}2.0 \\
0.6 \\
0\end{array}$ & \\
\hline
\end{tabular}

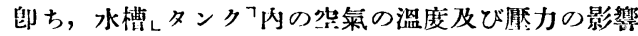

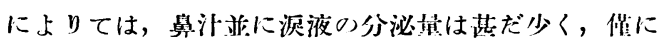
$3 \mathrm{mg}$ を越えない程度のもので，15分以上經過した時に
は分泌は眥無である.

\section{第一節 正常動物に於ける場合}

その成維は方表のやらである。

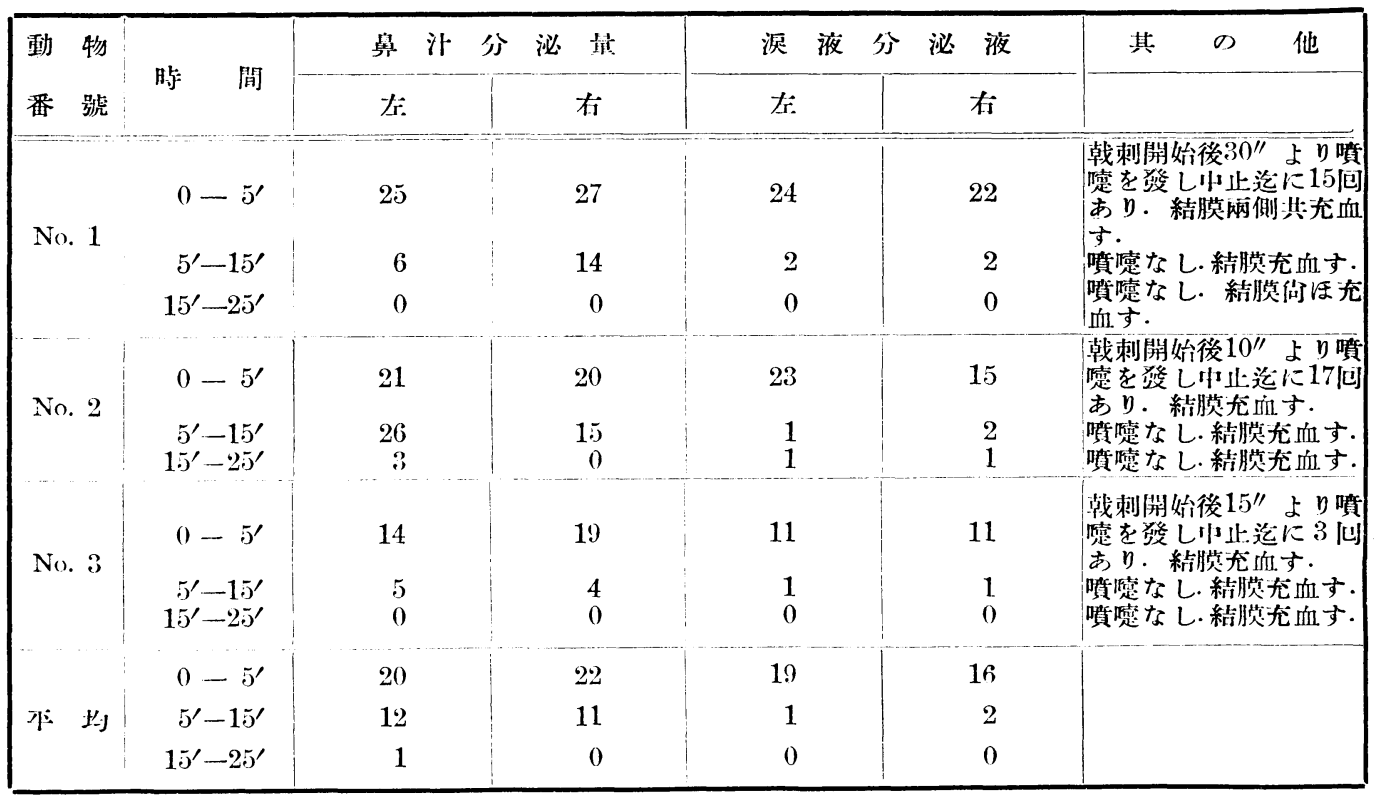

概括 最初の刺战開始後 5 分間は悬汁分泌は平均 20 一22mgである．洏して，その性質は必ず水樣性であ

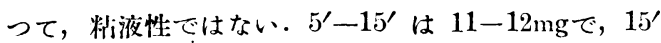
以後は殆ど涊めないかむつても極く少量である. 何れ
の場合でもその性質は水樣性である.淚液分泌量は刺 戟開始より5分間は $16-19 \mathrm{mg}$ で，5'-15’は唯に1一 $2 \mathrm{mg}$ で殆ど分泌を認めない.

第二節 一側頸部交㷋神經頸上節剔出啳に於ける場 
合

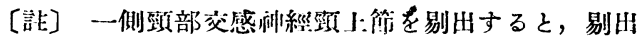

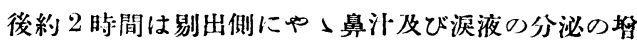
量するを認む。その量鼻汁は5分間に約 $2 \mathrm{mg}$ 涙液は
約 $4 \mathrm{mg}$ であるが，2 時間後は殆ど正常しに等しく なる．故に衰驗はいつも剔出後 2 時を經過てから行 s.

その成繦は次表のゅらである。

\begin{tabular}{|c|c|c|c|c|c|c|}
\hline 動 物 & & 鼻 汒 & 分 泌 量 & 淚 液 & 泌 量 & 其 \\
\hline 番 號 & & 對照側（左） & 剔出倒 (在) & 對照僛 (灰) & 剔出倒（有） & \\
\hline No. 1 & $\begin{array}{r}0-5^{\prime} \\
5^{\prime}-15^{\prime} \\
15^{\prime}-25^{\prime}\end{array}$ & $\begin{array}{l}18 \\
0 \\
0\end{array}$ & $\begin{array}{r}23 \\
2 \\
0 \\
\end{array}$ & $\begin{array}{r}10 \\
0 \\
0 \\
\end{array}$ & $\begin{array}{l}10 \\
3 \\
0\end{array}$ & 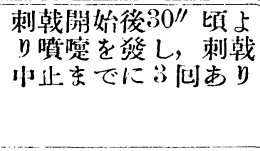 \\
\hline No. 2 & $\begin{array}{r}0-5^{\prime} \\
5^{\prime}-15^{\prime} \\
15^{\prime}-25^{\prime}\end{array}$ & $\begin{array}{l}6 \\
0 \\
0\end{array}$ & $\begin{array}{r}21 \\
3 \\
1\end{array}$ & $\begin{array}{r}54 \\
5 \\
0\end{array}$ & $\begin{array}{r}57 \\
5 \\
2\end{array}$ & $\begin{array}{l}\text { 刺戟や5 问の噴罟あ } \\
\text { り. }\end{array}$ \\
\hline No. 3 & $\begin{array}{c}0-5^{\prime} \\
5^{\prime}-15^{\prime} \\
15^{\prime}-25\end{array}$ & $\begin{array}{r}20 \\
3 \\
0\end{array}$ & $\begin{array}{r}27 \\
6 \\
1\end{array}$ & $\begin{array}{r}13 \\
2 \\
0\end{array}$ & $\begin{array}{r}18 \\
2 \\
1\end{array}$ & $\begin{array}{l}\text { 刺战小 } 8 \text { 们の噴菱あ } \\
\text { り. }\end{array}$ \\
\hline No. 4 & $\begin{array}{c}0-5^{\prime} \\
5^{\prime}-1 \check{J}^{\prime} \\
15^{\prime}-25^{\prime}\end{array}$ & $\begin{array}{r}23 \\
2 \\
0\end{array}$ & $\begin{array}{r}19 \\
1 \\
0\end{array}$ & $\begin{array}{l}6 \\
0 \\
0\end{array}$ & $\begin{array}{l}5 \\
1 \\
1\end{array}$ & 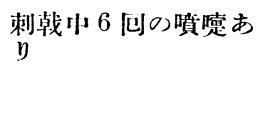 \\
\hline No. 5 & $\begin{array}{c}0-5^{\prime} \\
5^{\prime}-15^{\prime} \\
15^{\prime}-25^{\prime}\end{array}$ & $\begin{array}{r}20 \\
0 \\
0\end{array}$ & $\begin{array}{r}23 \\
2 \\
1\end{array}$ & $\begin{array}{l}3 \\
0 \\
0\end{array}$ & $\begin{array}{l}3 \\
1 \\
0\end{array}$ & $\begin{array}{l}\text { 刺战小13可の喷德沾 } \\
\text { り. }\end{array}$ \\
\hline 平 坋 & $\begin{array}{c}0-5^{\prime} \\
5^{\prime}-15^{\prime} \\
15^{\prime}-25^{\prime}\end{array}$ & $\begin{array}{r}17 \\
1 \\
0\end{array}$ & $\begin{array}{r}23 \\
3 \\
1\end{array}$ & $\begin{array}{r}17 \\
1 \\
0\end{array}$ & $\begin{array}{r}19 \\
2 \\
1\end{array}$ & \\
\hline
\end{tabular}

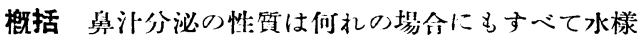
性である。その量は正常動物に於けると火症ない梯で

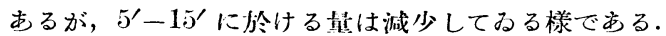
次に對照侧と剔仙侧との渠であるが，兩侧の變化比較 的少い樣であるが，その本均に於ては剔出侧に多い樣 である，淚液分泌は正常動物に於けるものと大瑯ない

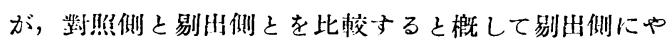

\多くなつてみる樣である。

第三節 一側がッセル氏神經節切獣後に於ける場合

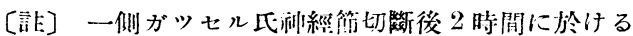
經過は鼻汁分泌に格別の變化を涊めない樣である。 然し切斷侧結脱は多少乾燥する。

损驗による成結は次のやうである。

\begin{tabular}{|c|c|c|c|c|c|c|}
\hline 動 物 & \multirow{2}{*}{ 時間 } & 鼻 汒 & 泌 量 & 淡 液 & 泌 全 & 其 \\
\hline 番 號 & & 㔂照倒 (广⿸丆口. & 剔出側 (有) & 對照㑬 (左) & 剔出㑬(不) & \\
\hline \multirow{3}{*}{ No. 1} & $0-5^{\prime}$ & 14 & 0 & 81 & 11 & \multirow{3}{*}{ 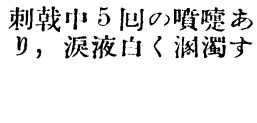 } \\
\hline & $5^{\prime}-15^{\prime}$ & 8 & 0 & 11 & 8 & \\
\hline & $15^{\prime}-25^{\prime}$ & 6 & 0 & 18 & 12 & \\
\hline \multirow{3}{*}{ No. 2} & $0-\bar{\partial}^{\prime}$ & 16 & 0 & 25 & 18 & \multirow{3}{*}{$\begin{array}{l}\text { 刺战山4 可の噴德む } \\
\text { ク. }\end{array}$} \\
\hline & $5^{\prime}-15^{\prime}$ & 7 & 0 & 12 & 9 & \\
\hline & $15^{\prime}-2 \overline{5}^{\prime}$ & 0 & 0 & 3 & 2 & \\
\hline
\end{tabular}




\begin{tabular}{|c|c|c|c|c|c|c|}
\hline No. 3 & $\begin{array}{c}0-5^{\prime} \\
5^{\prime}-15^{\prime} \\
15^{\prime}-25^{\prime}\end{array}$ & $\begin{array}{r}23 \\
5 \\
0\end{array}$ & $\begin{array}{l}0 \\
0 \\
0\end{array}$ & $\begin{array}{r}21 \\
15 \\
8\end{array}$ & $\begin{array}{r}13 \\
4 \\
3\end{array}$ & 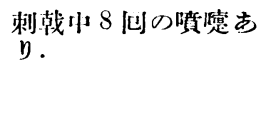 \\
\hline No. 4 & $\begin{array}{c}0-5^{\prime} \\
5^{\prime}-15^{\prime} \\
15^{\prime}-25^{\prime}\end{array}$ & $\begin{array}{r}17 \\
8 \\
0\end{array}$ & $\begin{array}{l}0 \\
0 \\
0\end{array}$ & $\begin{array}{r}12 \\
5 \\
3\end{array}$ & $\begin{array}{r}10 \\
5 \\
0\end{array}$ & $\begin{array}{l}\text { 刺战山2 } 2 \text { 问の噴嗦む } \\
\text { り. }\end{array}$ \\
\hline 平 均 & $\begin{array}{c}0-5^{\prime} \\
5^{\prime}-15^{\prime} \\
15^{\prime}-25^{\prime}\end{array}$ & $\begin{array}{r}18 \\
7 \\
1\end{array}$ & $\begin{array}{l}0 \\
0 \\
0\end{array}$ & $\begin{array}{r}22 \\
11 \\
8\end{array}$ & $\begin{array}{r}13 \\
7 \\
4\end{array}$ & \\
\hline
\end{tabular}

䧽括 分泌せられたる鼻汁の性質はすべて水樣性で ある.

對照側に於ける鼻汁分泌量は正常動物と大美ない栐

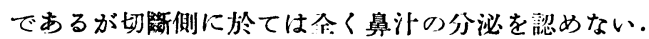
渗液の分泌は初めの5分間に於ては正常動物と大焦な い栐であるが $5^{\prime}-15^{\prime}$ 及 $15^{\prime}-25^{\prime}$ に於ては分泌量中 〉多い㥞である. 又對照侧との䧳は概して對照側に分 泌量多い樣である.
第四節 一側㥧面神經(中間神經)を延䯕より出たる 部に於て切斷したる媵に於ける場合

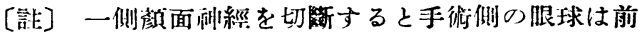

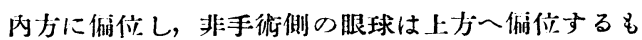
のである. 切断後は瞬目反射が沙火する．結膜の乾 燥度はガッセル氏洲經篮を切断したる埸合に比して 一屡苦し.

英驗による成絬は次のめうである。

\begin{tabular}{|c|c|c|c|c|c|c|}
\hline \multirow{2}{*}{\begin{tabular}{|l} 
動 物 \\
番 號
\end{tabular}} & \multirow{2}{*}{ 時間 } & \multicolumn{2}{|c|}{ 鼻 汁 分 泌量 } & \multicolumn{2}{|c|}{ 㴟 液 分 泌 量 } & 其 の 他 \\
\hline & & 粼照侧 (店) & 剔出側 (有) & 跱照㑬 (プ.) & 剔惧侧 ( & \\
\hline No. 1 & $\begin{array}{c}0-5^{\prime} \\
5^{\prime}-15^{\prime} \\
15^{\prime}-25^{\prime}\end{array}$ & $\begin{array}{r}13 \\
4 \\
1\end{array}$ & $\begin{array}{l}0 \\
0 \\
0\end{array}$ & $\begin{array}{r}24 \\
6 \\
2\end{array}$ & $\begin{array}{l}6 \\
0 \\
0\end{array}$ & $\begin{array}{l}\text { 刺戟小 } 3 \text { 问の噴喷あ } \\
\text { り. }\end{array}$ \\
\hline No. 2 & $\begin{array}{c}0-5^{\prime} \\
5^{\prime}-15^{\prime} \\
15^{\prime}-25^{\prime}\end{array}$ & $\begin{array}{r}25 \\
14 \\
7\end{array}$ & $\begin{array}{l}0 \\
0 \\
0\end{array}$ & $\begin{array}{r}21 \\
11 \\
3\end{array}$ & $\begin{array}{l}6 \\
3 \\
1\end{array}$ & 刺戟小噴嗦なし。 \\
\hline No. 3 & $\begin{array}{c}0-5^{\prime} \\
5^{\prime}-15^{\prime} \\
15^{\prime}-25^{\prime}\end{array}$ & $\begin{array}{r}13 \\
0 \\
0\end{array}$ & $\begin{array}{l}0 \\
0 \\
0\end{array}$ & $\begin{array}{l}9 \\
0 \\
0\end{array}$ & $\begin{array}{l}6 \\
0 \\
0\end{array}$ & 刺戟中噴嗦 4 仙あり. \\
\hline No. 4 & $\begin{array}{c}0-5^{\prime} \\
5^{\prime}-15^{\prime} \\
15^{\prime}-25^{\prime}\end{array}$ & $\begin{array}{r}17 \\
5 \\
1\end{array}$ & $\begin{array}{l}0 \\
0 \\
0\end{array}$ & $\begin{array}{r}21 \\
6 \\
3\end{array}$ & $\begin{array}{l}8 \\
0 \\
0\end{array}$ & 刺战小噴喷 6 们あり \\
\hline No. 5 & $\begin{array}{c}0-5^{\prime} \\
5^{\prime}-15^{\prime} \\
15^{\prime}-25^{\prime}\end{array}$ & $\begin{array}{r}14 \\
0 \\
0\end{array}$ & $\begin{array}{l}0 \\
0 \\
0\end{array}$ & $\begin{array}{r}17 \\
6 \\
2\end{array}$ & $\begin{array}{l}8 \\
3 \\
0\end{array}$ & 刺战中噴䖯 1 们あり \\
\hline 本 均 & $\begin{array}{c}0-5^{\prime} \\
5^{\prime}-15^{\prime} \\
15^{\prime}-25^{\prime}\end{array}$ & $\begin{array}{r}16 \\
5 \\
2\end{array}$ & $\begin{array}{l}0 \\
0 \\
0\end{array}$ & $\begin{array}{r}18 \\
6 \\
2\end{array}$ & $\begin{array}{l}7 \\
1 \\
0\end{array}$ & \\
\hline
\end{tabular}

概括 分泌せられたる鼻汁の性質はすべて水様性で ある.龂照侧の鼻汒分泌量は正常動物の場合と大倠な 
い樣であるが，切潞倒に於ては全く鼻汁の分泌を認め ない. 淚液分泌は初めの 5 分間は正常動物の埸合と大

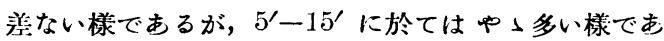
る.切到侧に於ても添液の分泌を認めるが對照侧との

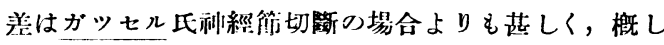
て㔂照侧に多い樣である。

\section{第三章 總括並に考按}

以上四篚の成縜を總括するに，正労動物之各 對!!你側との差異は大同小異であるが，莖部交感 神經锁上襒を剔出したるものでは剔州側にや」 网液の分泌量が多くなつて居る. 又ガツ七ル上

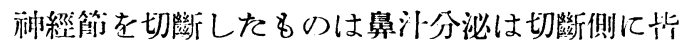
想で㳄液分泌は切斷側に減少してるる，一側の

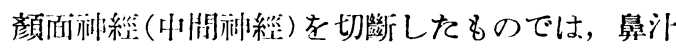
分泌は切斷側に紫䁩で淚液分泌は切斷側に著し く減少しみて，ガツ七ル氏刑經切断の場合より も苫しい橙である。

その他第一箱，第二简の賽驗の際には刺戟小

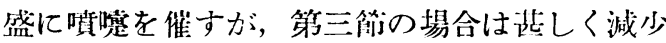
し，第四简の場合もや」少くなる栐である. 又

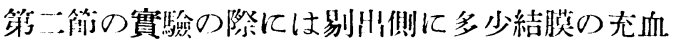
を認める，以上の成紹について教按してみるに

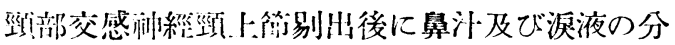
泌あるのに對し，Bertein は，艾感利經币には てれらに對する分泌繊維を们し，而8交感种經 勁邻除去後には鼻粘膜血管は收緮してるるか ら血管撗张による二次的の濾出ではないと云ひ， 份ほその纎維の刺戟は鼻粘膜脉から濃厚なっム チンフに富んた液を湧出せしめ, 反之副交感䀅經 の刺戟は鼻粘膜や上顎腺から二次的に燱液性の 滤川液と其に血管の演張を塋起せしめると述へ てみる. 反之 Jung は交感悯經勁上简は分泌に 對して抑制的に作瑚する故，てれを除去した後 には分泌が堆加するものである之云つてみる。

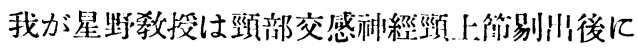
は鼻粘膜血管つ窑張を起すと述へられてるる.

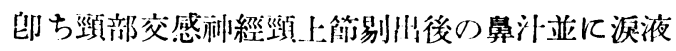
の分泌は杉柎血管の演張によるか，又は抑制纎 維の切斷によつて起るものかは米だ不明ではあ るが, 余は抑制纎維の切斷によるものと信ずる. 似となればレホルマリンフで鼻粘膜を刺戟すると 鼻粘偾や絬脱の血管は收絎するために（これは 余が犬で䆩驗したのであるが和學测經の刺戟に

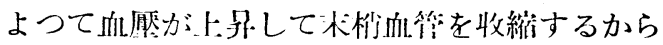
である）曼汒分泌や，淚液分泌が起るやうに思は れるが，乙の際第四畄の賽驗に於けるやうに一

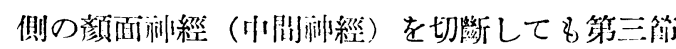

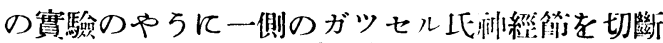

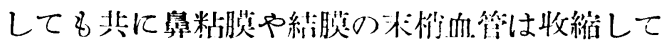
みるのに拘ら和同側の鼻汁分泌は全然起らない し，淚液分泌は餘程娍少するととからして朴杪 血管の收絎のために舅汇分泌や，淚液分泌は起

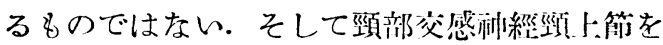

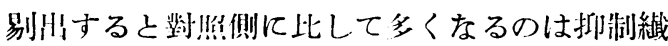
維の仿作を思はしぬるからである，然し第三， 第四の賽驗の場合でも于術側の淚液分泌が見ら

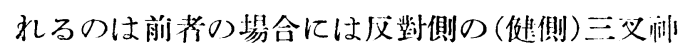
經によつて虽に咕した刺战は，同側の（于術

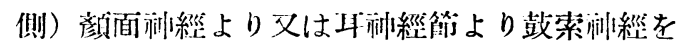
經て淚腺に逹したものであらら，父後者の場合

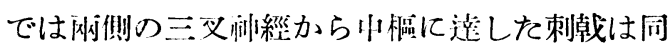

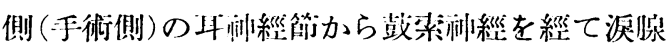
に茭したものであらう。そして第三简の場合よ りも第四简の場合の方が淚液分泌の少いのはや はり顏而测經が圭なる經路であるてとを祭しる のに䧼くはない，装之レホルマリンา 1 分润の刺

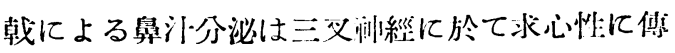


導せられ，同側の顏面神經のみによりて遠心性 几傳導せられるものである，次に涯液分泌は三 叉䄁經によりて求心性に僬染せられ，网側の顏 面利經 (中間利經) 及び耳栦經筬より鼓索科經に よりて遠心性に㒄導せられるものであらう。

\section{第四章 結 論}

1）レホルマリンフによる鼻粘膜の 1 分間刺戟 は水核性の鼻汒分泌渗液分泌を萑起せしむ。

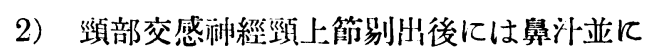

淚液分泌の增加を招來す。

3）ガツセル氏种經節切斷の後に上述鼻粘膜 刺棹を加ふるに淚液分泌はや」減少し鼻汒分泌 を招來せず。

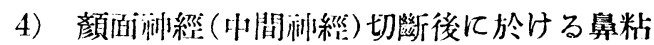
膜刺战は源液分泌を著しく減少せしぬ舅汒分泌 は遂に招來せず.

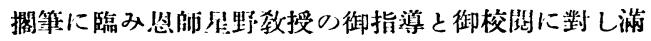
腔の謝意を表す。

\section{文背}

1) Aschenbrandt: Über den Einfluss der Nerven auf die Secretion der Nasenschleimhaut. Monatschrift Ohrenheikunde. 1885, 65. $\quad$ 2) Rossbach u. Aschenbrandt: Beiträge zur Physioloyie u. Pathologie der Schleimsecretion in den Luftwegen. Monatschrift Ohrenheilkunde. 1881, 41.

3) D. M. A.

Tschalussow : Die Innervation der Gefäss der Nasenschleimhaut. Pügers Archiv. Bd. 151, 1913.

Gaule: Physiologie der Nase und ihrer Nebenhöhlen. Ileymans I Landbuch der Laryngologie u. Rhinologie. 1900,3 .

5) Bertein, P.: Essai anatomo-clinique sur le systeme sympathique de la muqueuse pituitaire. Zbl. Inals-usw. Heilk. Bd. 8, 45.

6) Hédon: Lehrbuch der Physiologie (russ). Undritz: Über vasomotorische Reflexe der Nase. Zschr. f. Hals-usw. Heilk. Bd. 25.

8) Dartre,

A. and Morat, J. P.; Recherches experimentales sur le systeme nerveux vasomoteur. Paris g. masson, 1884. 9) Koblank: Die Nase als Reflexorgan. 10) Denker-Kahler: IIandbuch der I Ials-usw. I Heilk. Bd. I. $\quad$ 11) Olf Larsell, Ph. D and Ralph a. Tenton. M. D.: Sympathetic innervation of the nose. Archives of Oto-laryngology Bd. 24, 6.

12) Tatum, A. L.: Reflectorische vasomotorische Veränderung der Nasenschleimhaut. Zbl. Hals-usw. Heilk. Bd. 6. 13) E. Berthold : Fxperimentele Untersuchungen über den Einflusse der Nerven der Paukenhöhlen auf die Vascularis-ation und Secrtion über Schleimhaut. Zschr. Ohrenheilk. Bd. 10.

14) Frank: Varomotorische Effect von Reizungen der Nasenschleimhaut Mschr. Ohrenheilk. 1889.

（15 初岩：耳鼻臨林，30卷，4號.

61) 福武：阙 川醫學會雜誌, 2 兊, 4 號.

17) 吳：自律种經系.

19）松村：グレンツゲピート，4號.

22) 寺田：莡驗藥物學雜誌，2告，1號.

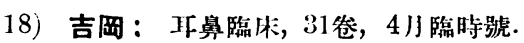
20）山崎：臨講, 73號.

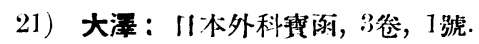

